\title{
ÉPOCA DE APLICAÇÃO, FONTES E DOSES DE POTÁSSIO NA CULTURA DA BATATA
}

\section{TIMING, SOURCES AND RATES OF POTASSIUM FERTILIZER APPLICATION FOR POTATO}

\author{
Volnei PAULETTI ${ }^{1}$ \\ Emilson MENARIM²
}

\begin{abstract}
RESUMO
Com o objetivo de avaliar o efeito de fontes, época de aplicação e doses de adubação potássica em batata (Solanum tuberosum L.), este ensaio foi conduzido na Fazenda Pinheirinho no município de Castro-Pr. Foram utilizadas duas fontes de potássio $\left(\mathrm{KCl} \mathrm{e} \mathrm{K}_{2} \mathrm{SO}_{4}\right.$ ) combinadas com duas épocas de aplicação ( $50 \%$ da aplicação em pré plantio mais $50 \%$ no sulco; e $50 \%$ no sulco, mais $50 \%$ na amontoa) e com doses de potássio $\left(0,200,400\right.$ e $600 \mathrm{~kg}$ de $\left.\mathrm{K}_{2} \mathrm{O} \cdot \mathrm{ha}^{-1}\right)$. O delineamento utilizado foi o fatorial $(2 \times 2 \times 4)$, com as parcelas dispostas em blocos ao acaso com quatro repetições. A cultivar Bintje, foi plantada com espaçamento de 0,75 m entre linhas e 0,30 m entre plantas e o preparo do solo foi feito de acordo com o recomendado para a cultura. Aos 64 dias após o plantio, coletaramse folhas para avaliar o teor de $\mathrm{P}, \mathrm{Ke} \mathrm{Cl}$. Avaliou-se a produtividade, o número de tubérculos totais, de tubérculos grandes e pequenos, o teor de matéria seca de 20 tubérculos grandes, o número de hastes por planta e de plantas da área útil. A aplicação de parte do $\mathrm{K}$ no sulco e parte em pré-plantio diminui o número de plantas em relação à aplicação de parte na amontoa. O número de batatas pequenas reduziu com maiores doses de $\mathrm{K}_{2} \mathrm{O}$, independentemente da fonte. A aplicação de doses crescentes de $\mathrm{KCl}$ resultou em aumento do teor foliar de cloro, redução da produtividade de tubérculos grandes e totais. A aplicação de sulfato de K proporcionou maior teor foliar de $\mathrm{K}$ que a aplicação de cloreto. $\mathrm{O}$ aumento dos teores foliares de $\mathrm{Ke} \mathrm{Cl}$ diminuíram a matéria seca dos tubérculos afetando sua qualidade.
\end{abstract}

Palavras-chave: batata, potássio, sulfato de potássio, cloreto de potássio, cloro.

\begin{abstract}
With objective to evaluate the effect of different potassium sources, timing and rates for potato (Solanum tuberosum L.), an experiment was established at Pinheirinho farm, Castro county, Parana State - Brazil. The experiment was set out in an randomized complete block factorial design, with four replications. Treatments consisted of a factorial combination of two potassium sources $(\mathrm{KCl}$ and $\mathrm{K}_{2} \mathrm{SO}_{4}$ ), two timing $\mathrm{K}$ application (50\% of the application before more $50 \%$ during planting and $50 \%$ during de planting more $50 \%$ during ridge) and four potassium rates $\left(0,200,400\right.$ and $600 \mathrm{~kg}$ of $\left.\mathrm{K}_{2} \mathrm{O} / \mathrm{ha}\right)$, respectively. The most traditional regional crop, Bintje, was planted $0,75 \mathrm{~m}$ by $0,30 \mathrm{~m}$. It was evaluated the leaf nutrient concentration ( $\mathrm{P}, \mathrm{K}$ and $\mathrm{Cl}$ at 64 days after the planting), yield, number total tuber, number of big and small tuber, dry matter for big tuber, branch number by plant and plants by plot. The application $50 \%$ of before planting more $50 \%$ during planting diminished the potato population compared to application of $50 \%$ during de planting more $50 \%$ during ridge. Regardless potassium source, there was a reduction in the number small tuber in high potassium rate. Crescent KCl use provided increase leaf $\mathrm{Cl}$ concentration and decrease total yield and big tubers. Application of potassium sulfate provided higher leaf $\mathrm{K}$ concentration than potassium chloride. Inverse relationship between leaf $\mathrm{K}$ and $\mathrm{Cl}$ concentration and tuber dry matter, diminishing tuber quality.
\end{abstract}

Key-words: potato, potassium, potassium sulfate, potassium chloride.

\footnotetext{
${ }^{1}$ Engenheiro Agrônomo, M. Sc., (CREA 24.007-D), Coordenador do Setor de Fertilidade de Solos, Fundação ABC, Rodovia Pr 151, Km 288 - Cx Postal 1003 - CEP: 84166-990, Castro - PR, E-mail: vpauletti@fundacaoabc.com.br

²Engenheiro Agrônomo (CREA 32674 /D), Cooperativa Agropecuária Castrolanda, Castro - PR, Responsável Técnico Unidade Batata Semente.
} 


\section{INTRODUÇÃO}

A batata (Solanum tuberosum L.) é a hortaliça de maior importância comercial no Brasil. A bataticultura é a principal atividade econômica em muitas regiões. Os estados do Paraná, São Paulo, Minas Gerais, Santa Catarina e Rio Grande do Sul são responsáveis por $95 \%$ da produção do tubérculo. No Paraná, destacam-se as regiões de Guarapuava, Região Metropolitana de Curitiba e Castro (FERRAZ, 1995) ${ }^{3}$. Em Castro, o cultivo da batata teve início em 1990, sendo difundida pela Sociedade Cooperativa Castrolanda como mais uma opção comercial de verão, além das já tradicionais do município (milho, soja e feijão) (MOLIN e GREIN, 1995) ${ }^{4}$.

A batata é um importante alimento, principalmente como fonte de amido. Geralmente, a cultura recebe altas doses de adubo potássico por ser o nutriente mais exigido pela planta, além de que a falta de potássio compromete a formação do amido, que faz parte de sua constituição (3).

$\mathrm{Na}$ cultura da batata doses crescentes de nitrogênio $(N)$, fósforo $(P)$ e potássio $(K)$, até 2 t.ha $^{-1}$ em batata semente e acima de 3,5 t.ha ${ }^{-1}$ em batata consumo, proporcionaram aumento de produção (11). Porém, neste trabalho foram utilizadas doses de uma formulação contendo $\mathrm{N}, \mathrm{P}$ e K, não sendo possível atribuir o efeito ao $\mathrm{K}$, especialmente em função do teor inicial do solo ser de $2,8 \mathrm{mmol} \cdot \mathrm{dm}^{-3}$. Observou-se a máxima produção de tubérculos com a aplicação de $353,4 \mathrm{~kg} \cdot \mathrm{ha}^{-1}$ de $\mathrm{K}_{2} \mathrm{O}$ em área com $1,36 \mathrm{mmol}_{\mathrm{c}} \cdot \mathrm{dm}^{-3}$ (5).

No entanto vários autores não encontraram resposta em produção de tubérculos à aplicação de $\mathrm{K}$ na cultura da batata, com influência negativa no teor de matéria seca $(10 ; 2)$, e de amido (8)

$\mathrm{Em}$ solo com $1,4 \mathrm{mmol} \cdot \mathrm{dm}^{-3}$ de $\mathrm{K}$, não se observou efeito de doses de $\mathrm{K}^{\mathrm{c}}$ sobre o número de hastes, folhas e tubérculos, mas apenas no aumento do comprimento da haste (7).

A fonte de adubação potássica, cloreto ou sulfato, não alterou significativamente a produtividade, a densidade, a porcentagem de matéria seca, a qualidade de fritura e a classificação comercial dos tubérculos (MOLIN e GREIN, 1995) ${ }^{4}$.

Em adubações excessivas, com o aumento da absorção e acúmulo de $\mathrm{K}$ na planta, há redução do potencial osmótico e aumento da absorção de água, o que causa diluição dos teores de matéria seca e de amido nos tubérculos (7).

O objetivo deste trabalho foi avaliar o efeito de fontes, épocas de aplicação e doses de K sobre o rendimento, teor de matéria seca (MS) e teores foliares de fósforo $(\mathrm{P})$, potássio $(\mathrm{K})$, e cloro $(\mathrm{Cl})$ em batata.

${ }^{3}$ FERRAZ, M. V. A Cultura da Batata (Solanum tuberosum L.). Castro: Castrolanda. 1995. 30 p. (Relatório interno).

${ }^{4}$ MOLIN, R. \& GREIN, O. J. Avaliação de Estratégias de Adubação na Cultura da Batata ((Solanum tuberosum L.) cv. Agria. Castro: Fundação ABC, 1995. 18 p. (Relatório interno).

\section{MATERIAL E MÉTODOS}

O experimento foi instalado na Fazenda Pinheirinho, município de Castro-PR, nas coordenadas geográficas de $-24^{\circ} 40^{\prime} 38^{\prime \prime}$ latitude, -4941'02" longitude e $955 \mathrm{~m}$ de altitude, em solo classificado como CAMBISSOLO HÁPLICO Distrófico típico, textura argilosa, relevo suave ondulado (1). O clima regional é classificado como Cfb (Clima subtropical úmido), segundo a classificação de Köeppen. Na Figura 1 está representada a precipitação e as temperaturas máximas e mínimas, ocorridas na região nos meses correspondentes ao ciclo cultural da batata. Entre o plantio e a colheita o total de precipitação foi de $652,6 \mathrm{~mm}$.

A análise química do solo, na camada de 0 a $20 \mathrm{~cm}$ de profundidade revelou as seguintes características: $\mathrm{pH}\left(\mathrm{CaCl}_{2}\right)=5,8 ; \mathrm{P}$ (resina) $=37 ; \mathrm{Cu}=0,8$; $\mathrm{Fe}=4,2 ; \mathrm{Mn}=1,2 ; \mathrm{Zn}=0,6$, expressos em mg.dm ${ }^{-3} . \mathrm{Em}$ $\mathrm{mmol}_{\mathrm{c}} \cdot \mathrm{dm}^{-3}, \mathrm{~K}=3,7 ; \mathrm{H}+\mathrm{Al}=42 ; \mathrm{CTC}=131,7 ; \mathrm{Al}=0,0$; $\mathrm{Ca}=51 ; \mathrm{Mg}=35$. A análise física revelou os seguintes teores: 530, 200, e 270 g. $\mathrm{kg}^{-1}$ de areia, silte e argila, respectivamente.

O preparo do solo consistiu de uma aração, duas escarificações cruzadas, e uma passagem de grade niveladora.

A cultivar Bintje, tardia, com ciclo médio de 110 dias, foi plantada em 01/10/99, com espaçamento de $0,75 \mathrm{~m}$ entre linhas e $0,30 \mathrm{~m}$ entre plantas. Comum aos tratamentos, realizou-se a aplicação de $120 \mathrm{~kg} \mathrm{ha}^{-1}$ de $\mathrm{Ne}$ 450 kg.ha-1 de $\mathrm{P}_{2} \mathrm{O}_{5}$ no sulco Foram efetuados os tratos culturais de controle de pragas, doenças e plantas daninhas adequados à região. Durante o ciclo da cultura, na fase de tuberização, foram realizadas duas irrigações para evitar qualquer sintoma de deficiência hídrica (murcha), apesar da precipitação ter sido regular, conforme apresentado na Figura 1.

O delineamento experimental utilizado foi o de blocos ao acaso com 4 repetições em esquema fatorial (2x2x4), combinando 4 doses de $\mathrm{K}_{2} \mathrm{O}(0,200,400$ e 600 $\mathrm{kg} \cdot \mathrm{ha}^{-1}$ ), 2 épocas de aplicação ( $50 \%$ aplicado no sulco mais $50 \%$ aplicado 13 dias antes do plantio e incorporado com grade e; $50 \%$ aplicado no sulco mais $50 \%$ aplicado na amontoa aos 33 dias após o plantio) e duas fontes de potássio (sulfato $-\mathrm{K}_{2} \mathrm{SO}_{4}$ e cloreto $-\mathrm{KCl}$ ).

Cada parcela foi constituída de quatro linhas com cinco metros de comprimento $\left(15 \mathrm{~m}^{2}\right)$, sendo a área útil correspondente às duas linhas centrais com quatro metros de comprimento $\left(6,0 \mathrm{~m}^{2}\right)$.

Aos 64 dias após o plantio coletou-se a primeira folha madura a partir do ápice para a base em 35 plantas, para a análise de $\mathrm{P}, \mathrm{K} \mathrm{e} \mathrm{Cl}$.

A colheita da área útil foi realizada no dia 20/02/2000. Avaliou-se a produtividade, número total de tubérculos, de tubérculos grandes (diâmetro superior a $42 \mathrm{~mm}$ ) e pequenos (diâmetro inferior a 42 
$\mathrm{mm}$ ), o teor de matéria seca de 20 tubérculos grandes coletados aleatoriamente entre os colhidos, e o número de hastes por planta e de plantas da área útil. Os dados obtidos foram submetidos à análise de variância. Quando houve efeito somente da época e fonte, aplicou-se o teste de Tukey a $5 \%$ de probabilidade. Quando houve efeito de dose ou das interações entre dose $x$ época e dose $x$ fonte, aplicou-se o teste de correlação e após este, o de regressão.

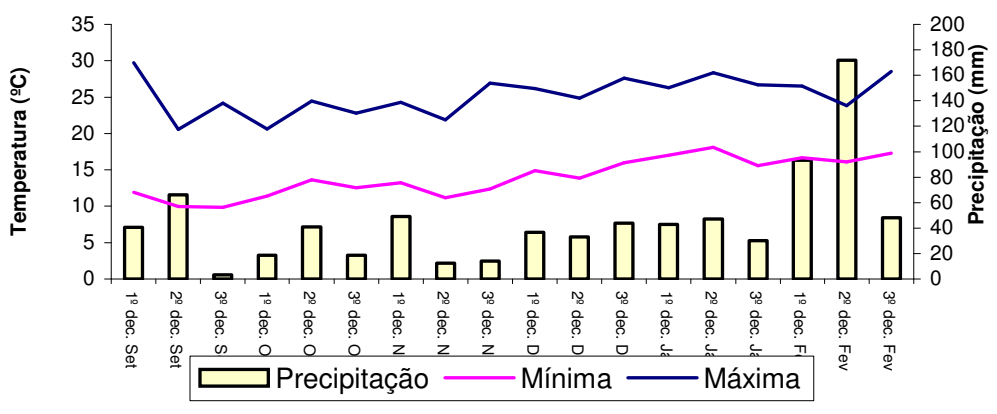

FIGURA 1 - Precipitação pluviométrica $(\mathrm{mm})$, temperaturas máximas e mínimas $\left({ }^{\circ} \mathrm{C}\right)$, por decêndios, durante o período de cultivo da batata, em Castro - PR, no ano agrícola de 1999/2000.

\section{RESULTADOS E DISCUSSÃO}

Os tratamentos não influenciaram o número de hastes, número de tubérculos grandes e totais por planta, produtividade de tubérculos pequenos e o teor foliar de fósforo (Tabela 1).

O número de plantas por parcela foi influenciado apenas pela época, sendo superior $(p \leq 0,04)$ quando parte da aplicação foi feita na amontoa $(18,59)$, em relação à pré-plantio $(18,06)$ independentemente da fonte de K utilizada, tendo esse parâmetro um coeficiente de variação de $5,37 \%$. Esse fato pode ter relação com altas concentrações de $\mathrm{K}$ no solo que poderiam, por efeito salino, causar desidratação das sementes. A diminuição do número de plantas não afetou o número de hastes, que não variou com os tratamentos.

TABELA 1 - Número de hastes por planta (Nhastes), número de tubérculos grandes (Ntubgr) e totais (Ntubtt) por planta, produtividade de tubérculos pequenos (Prodtubpeq) e teor de P foliar ( $P$ foliar) em batata, em função da aplicação de fontes, épocas e doses de potássio.

\begin{tabular}{llccccc}
\hline Descrição & Nhastes & Ntubgr & Ntubtt & Prodtubpeq & Pfoliar \\
\hline \multirow{2}{*}{ Fonte } & Sulfato de K & 5,24 & 6,28 & 13,60 & 6658 & g.kg-1 \\
& Cloreto de K & 5,00 & 5,96 & 12,73 & 6886 & 2,56 \\
\hline & Prob>F & 0,1 & 0,37 & 0,1 & 0,59 & 0,94 \\
\hline Epoca & Antes plantio + sulco* & 5,14 & 6,09 & 13,31 & 6764 & 2,60 \\
& Sulco + amontoa** & 5,11 & 6,15 & 13,02 & 6779 & 2,52 \\
\hline & Prob>F & 0,8 & 0,87 & 0,56 & 0,97 & 0,36 \\
\hline Dose*** & 0 & 5,04 & 5,72 & 13,74 & 6917 & 2,68 \\
& 200 & 5,05 & 5,88 & 12,80 & 6417 & 2,49 \\
& 400 & 5,22 & 6,54 & 13,26 & 7208 & 2,66 \\
& 600 & 5,18 & 6,33 & 12,84 & 6544 & 2,43 \\
\hline & Prob>F & 0,72 & 0,33 & 0,51 & 0,53 & 0,15 \\
\hline Média & & 5,12 & 6,12 & 13,16 & 6772 & 2,56 \\
CV\% & 10,9 & 23,23 & 15,02 & 24,64 & 13,8 \\
\hline
\end{tabular}

${ }^{*} 50 \% 13$ dias antes do plantio e incorporado com grade $+50 \%$ no sulco de plantio; $* 50 \%$ no sulco de plantio $+50 \%$ na amontoa 33 dias após plantio; ${ }^{* \star \star}$ Doses de $\mathrm{K}_{2} \mathrm{O}$ kg.ha ${ }^{-1}$. 
PAULETTI, V.; MENARIN, E. Época de aplicação, fontes e doses de...

$\mathrm{O}$ aumento nas doses de $\mathrm{KCl}$ resultou em maiores teores de $\mathrm{Cl}$ nas folhas, enquanto o aumento nas doses de sulfato não afetou este teor (Figura 2).
A aplicação na amontoa $\left(0,91 \mathrm{~g} \cdot \mathrm{kg}^{-1}\right)$ proporcionou maior teor $(p \leq 0,01)$ em relação à aplicação em préplantio $\left(0,76 \mathrm{~g}^{\mathrm{kg}}{ }^{-1}\right)$.

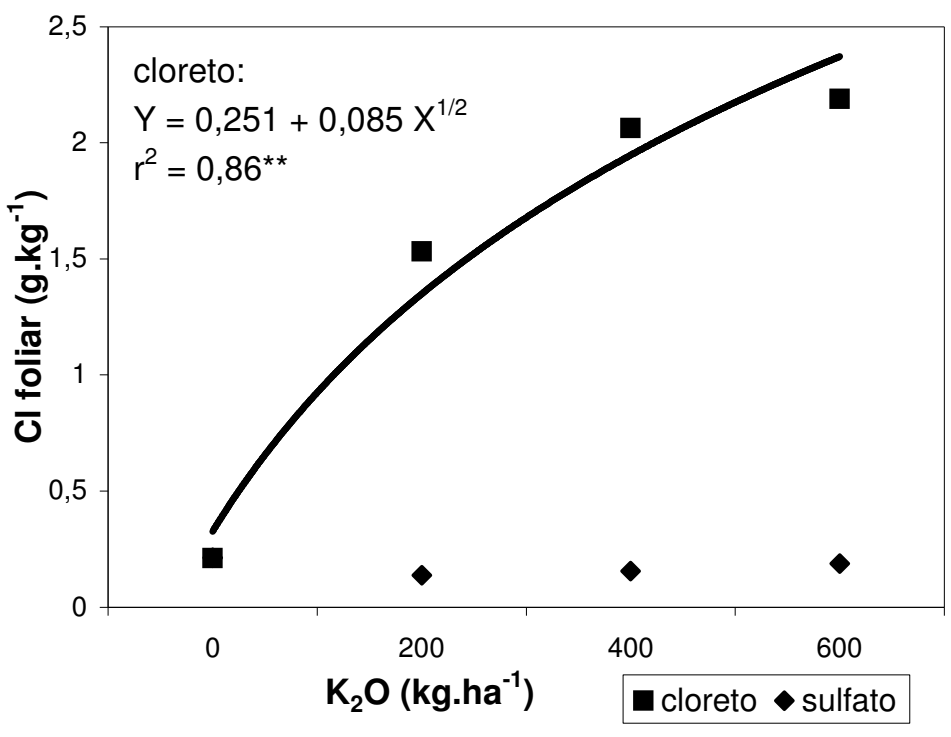

FIGURA 2 - Teor foliar de cloro em função da aplicação de fontes e doses de K.

$\mathrm{O}$ teor de $\mathrm{K}$ nas folhas foi influenciado tanto pela fonte quanto pelas doses aplicadas desse nutriente. Com a aplicação de sulfato, o teor foliar foi de $31,1 \mathrm{~g} . \mathrm{Kg}^{-1}$, significativamente superior $(\mathrm{p} \leq 0,01)$ ao observado com a aplicação de cloreto $\left(27,7 \mathrm{~g} \cdot \mathrm{Kg}^{-1}\right)$. O teor foliar de $\mathrm{K}$ teve um pequeno aumento com o acréscimo da dose independente da fonte utilizada (Figura 3).

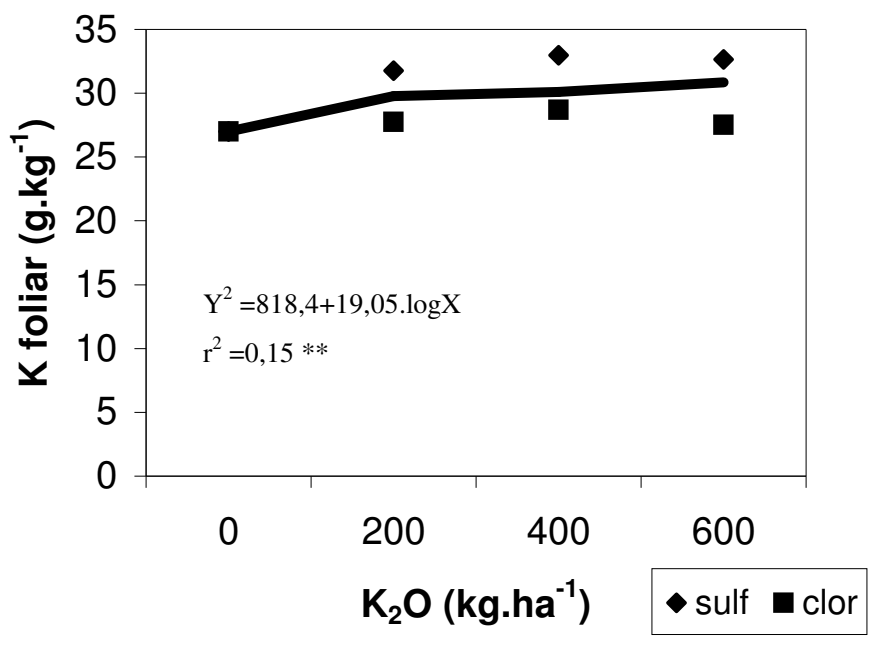

FIGURA 3 - Teor foliar de potássio de acordo com a aplicação de fontes e doses de K. 
Apesar deste aumento, os teores estão abaixo dos obtidos como nível critico (11) de $42,3 \mathrm{~g} . \mathrm{Kg}^{-1}$, quando avaliadas todas as folhas das plantas. Para obter teores acima deste valor, foram aplicados $200 \mathrm{Kg} \cdot \mathrm{ha}^{-1} \mathrm{~K}_{2} \mathrm{O}$ (11).

Este aumento do teor de $\mathrm{K}$ nas folhas está correlacionado com a diminuição do teor de MS dos tubérculos $\left(r=-0,50^{* *}\right)$. O aumento do teor de $\mathrm{K}$ pode ocasionar excesso de retenção de água no tubérculo e conseqüentemente menor valor comercial do produto pela redução do teor de matéria seca (4).
Quanto ao teor de MS nos tubérculos, a adição de sulfato não interferiu, contudo a adição crescente de cloreto reduziu esse teor (Figura 4), fato concordante com outros autores $(8,2)$. Observou-se redução de MS na maioria dos locais estudados quando a fonte foi o cloreto, fato que não ocorreu quando a fonte foi o sulfato (6). A correlação significativa e negativa $\left(r=-0,63^{\star \star}\right)$ entre $o$ teor foliar de $\mathrm{Cl}$ e a MS dos tubérculos, indica o efeito negativo deste elemento na qualidade do tubérculo. A equação que expressa esta relação é $\mathrm{Y}(\mathrm{MS})=21,08-2,48 . \mathrm{X}^{1 / 2}$ $\left(r^{2}=0,42^{* *}\right)$.

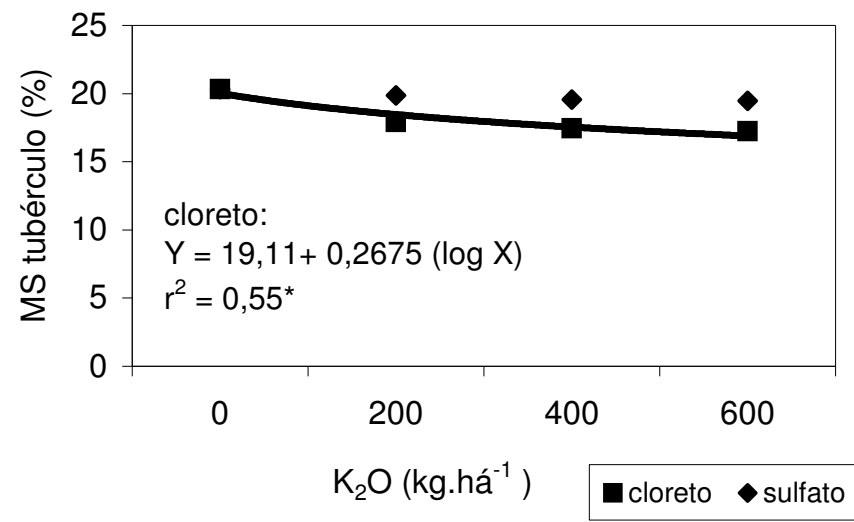

FIGURA 4 - Teor de matéria seca dos tubérculos em função da aplicação de doses e fontes de K.

O número de tubérculos pequenos, no entanto apresentou correlação negativa $\left(r=-0,30^{*}\right)$ com o acréscimo de $\mathrm{K}$, independente da fonte, fato que demonstra a importância da adubação potássica quando se deseja reduzir a presença desta classe de tubérculos. A diminuição do número de tubérculos pequenos não se refletiu em aumento do número de tubérculos grandes, que não foi afetado pela aplicação de $\mathrm{K}$.

A produtividade de batatas grandes não foi influenciada quando se aplicou $\mathrm{K}_{2} \mathrm{SO}_{4}$. Este fato pode ser explicado pelo alto teor de $\mathrm{K}$ no solo verificado na análise antes da implantação do experimento $\left(3,7 \mathrm{mmol}_{\mathrm{c}} \cdot \mathrm{dm}^{-3}\right)$, determinante para a baixa resposta à adubação potássica. Estes dados concordam com os já relatados por outros autores que obtiveram como nível crítico o teor de $2,7 \mathrm{mmol} \cdot \mathrm{dm}^{-3}$ de $\mathrm{K}$ no solo, acima do qual as respostas a adubação potássica são menos prováveis (6). Porém quando a fonte foi o cloreto a produtividade foi reduzida (Figura 5 ).

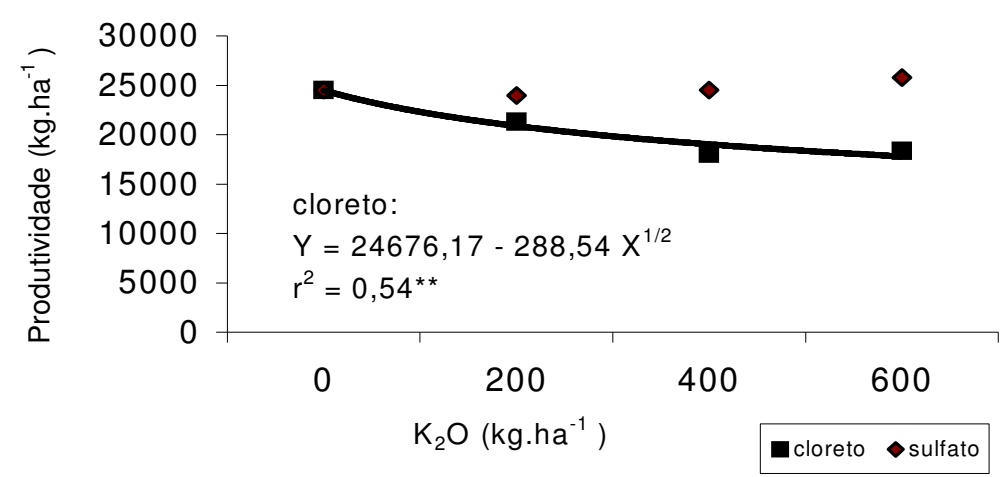

FIGURA 5 - Produtividade de tubérculos grandes de batata em função de fontes e doses de K. 
PAULETTI, V.; MENARIN, E. Época de aplicação, fontes e doses de...

A produtividade total de batata não foi influenciada pelo acréscimo da dose de $\mathrm{K}$ quando a fonte foi o sulfato, mas foi reduzida com a aplicação de cloreto (Figura 6), comportamento semelhante ao observado para tubérculos grandes (Figura 5).

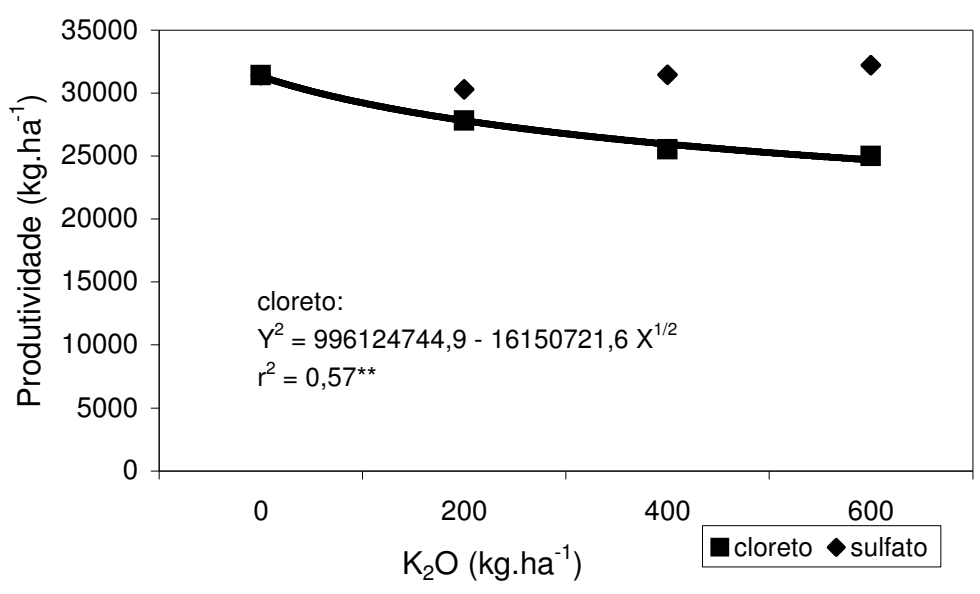

FIGURA 6 - Produtividade total de batatas em função de doses e fontes de Kutilizadas.

Com estas observações pode-se inferir que a adubação potássica, para teor de potássio no solo de $3,7 \mathrm{mmol}_{\mathrm{c}} \cdot \mathrm{dm}^{-3}$, proporcionou queda de matéria seca pelo aumento da absorção de $\mathrm{K}$, sem aumentar a produtividade, no caso da fonte sulfato, ou queda na produtividade e na matéria seca, no caso da fonte cloreto.

\section{CONCLUSÕES}

1 - A aplicação de parte do K em pré-plantio proporcionou menor número de plantas que na amontoa.

2 - A aplicação de cloreto de potássio aumentou o teor foliar de cloro.

3 - A aplicação de sulfato de potássio proporcionou maior teor foliar de $\mathrm{K}$ que a aplicação de cloreto.

4 - A matéria seca dos tubérculos diminuiu com os aumentos dos teores foliares de $\mathrm{K} \mathrm{e} \mathrm{Cl}$.

5 - A produtividade de tubérculos grandes (> $42 \mathrm{~mm}$ ) e total não foi afetada com a aplicação de $\mathrm{K}$ na forma de sulfato, mas diminuiu com a aplicação de cloreto.

\section{REFERÊNCIAS BIBLIOGRÁFICAS}

1. BOGNOLA, I.A.; FASOLO, P.J.; RAMOS,D.P. Solos e sua ambiência no foco de agricultura de precisão. Castro Embrapa, Fundação ABC, Ministério da Agricultura Pecuária e Abastecimento, 2001. 86 p.

2. CASTRO, C.A. Produtividade e qualidade de duas culturas de batata: resposta à adubação azotada e potássica. Revista de Ciências Agrárias, Lisboa, vol.17, n.4, p.15-25, 1994.

3. CHAPMAN, K. S. R.; SPARROW L. A.; HARDMAN, P. R.; WRIGHT, D. N.; THORP, J. R. A. Potassium nutrition of Kennebec and Russet Burbank Potatoes in Tasmania: effect of soil and fertilizer potassium on yield, petiole and tuber potassium concentrations, and tuber quality. Australian Journal of Experimental Agriculture, v. 32, p. 521-527, 1992.

4. DAVENPORT, J. R. Potassium and Specific Gravity of Potato Tubers. Better Crops, v.84, p.14-15. Georgia, 2000.

5. FONTES, P.C.R.; REIS JR., R.A.; PEREIRA, P.R.G. Critical potassium concentration and potassium/calcium plus magnesium ratio in potato petioles associated with maximum tuber yelds. Journal of Plant Nutrition, v. 19, p. 657-667, 1996.

6. PANIQUE, E.; KELLING, K. A.; SCHULTE, E. E.; HERO D. E.; STEVENSON, W. R.; JAMES, R. V. Potassium Rate and Source Effects on Potato Yield, Quality, and Disease Interaction. American Potato Journal, E.U.A., v.74, p.379-398, 1997.

7. REIS JÚNIOR, R. A.; FONTES, P. C. R. Morfologia e partição de assimilados na batateira em função de época de amostragem e de doses de potássio. Pesquisa Agropecuária Brasileira. Brasília, vol.34, n. 5, p. 795-799, 1999.

8. REIS JÚNIOR, R. A.; FONTES, P. C. R. Qualidade de Tubérculos de Batata cv. Baraka em Função da Adubação Potássica. Horticultura Brasileira, Brasília, v. 2, p.170-174, 1996.

9. REIS JÚNIOR, R. A.; MONNERAT, P. H. Nutrient concentrations in potato stem, petiole and leaflet in response to potassium fertilizer. Scientia Agrícola. Piracicaba, v. 57, n. 2, 2000.

10. SANGOI, L.; KRUSE, N.D. Doses crescentes de nitrogênio, fósforo e potássio e características agronômicas da batata em dois níveis de ph. Pesquisa Agropecuária Brasileira. Brasília. v.29, n. 9, p. 1333-1343, 1999.

11. TRANNI, P.E.; HIROCE, R.; BATAGLIA. O.C. Análise foliar: amostragem e interpretação. Campinas: Fundação Cargil, 18 p. 1983. 